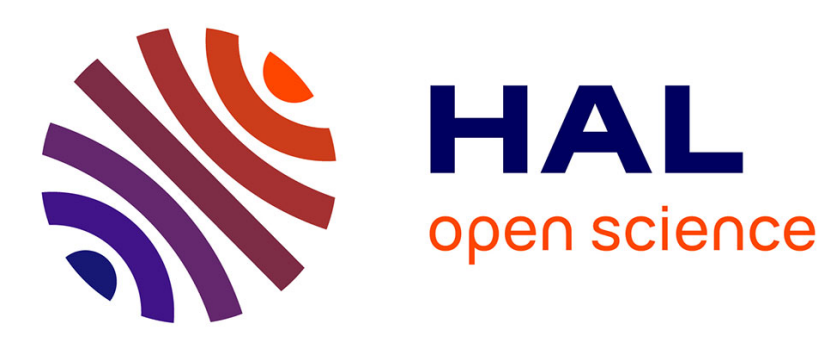

\title{
THE INTERFACE STRUCTURE OF THE S' PHASE IN AN Al (CuMg) ALLOY
}

\author{
H. Ye
}

\section{To cite this version:}

H. Ye. THE INTERFACE STRUCTURE OF THE S ' PHASE IN AN Al (CuMg) ALLOY. Journal de Physique Colloques, 1990, 51 (C1), pp.C1-373-C1-378. 10.1051/jphyscol:1990159 . jpa-00230321

\section{HAL Id: jpa-00230321 https://hal.science/jpa-00230321}

Submitted on 1 Jan 1990

HAL is a multi-disciplinary open access archive for the deposit and dissemination of scientific research documents, whether they are published or not. The documents may come from teaching and research institutions in France or abroad, or from public or private research centers.
L'archive ouverte pluridisciplinaire HAL, est destinée au dépôt et à la diffusion de documents scientifiques de niveau recherche, publiés ou non, émanant des établissements d'enseignement et de recherche français ou étrangers, des laboratoires publics ou privés. 
THE INTERFACE STRUCTURE OF THE S! PHASE IN AN Al (CuMg) ALLOY

\author{
H.Q. YE \\ Center of Condensed Matter and Radiation Physics, CCAST (World \\ Laboratory), Beijing \\ Laboratory of Atomic Imaging of Solids, Institute of Metal Research, \\ Academia Sinica, Shenyang 110015, P.R. China
}

\begin{abstract}
The interface structure between the S' precipitates and the Al matrix in a 2024 aluminium alloy with 4.43 wt\% Cu and 2.00 wt\% Mg has been investigated by means of high resolution electron microscopy (HREM). For the preferential S' precipitates with lath-shape, two features on the interface (001) $\mathrm{s}^{\prime}-(01 \overline{2}) \mathrm{m}$ can be recognized: 1 . coherent match along the [010] s' and [021]m directions; 2. step structure with single unitcell in height and 4-6 unitcells in width. Based upon the HREM micrographs with interpretable resolution better than $0.2 \mathrm{~nm}$ and a detailed analysis of the crystal structure of the $s^{\prime}$ phase, the atomic configuration of the (001) $s^{\prime}-(01 \overline{2}) m$ interface structure is also presented.
\end{abstract}

\title{
I - INTRODUCTION
}

The precipitating phase in the common age-hardenable aluminium alloys containing $\mathrm{Cu}$ and $\mathrm{Mg}$ as the main strengthening elements has been identified as the $\mathrm{S}^{\prime}$ phase when the Cu/Mg ratio is larger than 2.2/1/. The $S^{\prime}$ phase is approximately the same as the equilibrium S phase, namely the Al (cumg) intermetallic compound. The subtle distinction between the $S^{\prime}$ and $S$ phases originally was drawn by the Laue patterns of X-ray diffraction. However, no detailed data of the crsytal structure of the $S^{\prime}$ phase have been reported yet. In literatures the precipitates formed below $250^{\circ} \mathrm{C}$ are normally denoted as the $\mathrm{S}^{\prime}$ phase and their crystal structure was described in terms of one of the $S$ phase. The $S$ phase belongs to an orthorhombic system with the Cmcm space group and lattice constants of $a=0.400 \mathrm{~nm}, b=0.923 \mathrm{~nm}$ and $c=0.714 \mathrm{~nm} / 2 /$. The orientation relationships between the $S^{\prime}$ phase and matrix were well established by $X-r a y$ diffraction data /1/ as follows:

$$
\text { [100] s'// [100]m, I010] s'// [021]m, [001] s'// [01 } \overline{2}] \mathrm{m} \text {. }
$$

The S' phase has a rod or lath-shape lying on the i012\}m planes along <100>m directions $/ 3,4 /$. According to the precipitate-matrix orientation relationship the plane misfit can be dalculated as:

$$
\begin{aligned}
& \left(d(200) m-d(100) s^{\prime}\right), / d(200) m=1.21 \% \text { for }(100) s^{\prime}-(100) m \text { connection; } \\
& \left(5 * d(021) m-d(010) s^{\prime}\right) / 5 * d(021) m=-1.95 \% \text { for }(010) s^{\prime}-(021) m \text { connection; } \\
& \left(4 * d(012) m-d(001) s^{\prime}\right) / 4 * d(012) m=1.42 \% \text { for }(001) s^{\prime}-(012) m \text { connection. }
\end{aligned}
$$

The longest dimension of the precipitate should be related to the least misfit and this is tha case of the $s^{\prime}$ phase. The long direction of the s' rods or laths is always the [100]s' axis. The widest direction of the s' laths may be

*Mail address 
the [001] s' axis according to the plane misfit analysis and this could not be identified from the diffraction contrast images with moderate resolution. Recently the [100l lattice image of the S' phase clearly showed that the $S^{\prime}$ laths grew normally along their [010] axes with a rather flat interface at the $(001) s^{\prime}-(01 \overline{2}) m$ boundary. Because the edge on orientation of the (001) $\mathrm{s}^{1}-(01 \overline{2}) \mathrm{m}$ interface is the $[100] \mathrm{m}$ direction, the main difficulty for investigating the interface structure is the close distance of $0.202 \mathrm{~nm}$ between atom columns in the Al matrix when one viewed the specimen along the [100] direction. In this work high resolution images of the $S^{\prime}$-matrix interface are presented with suitable resolution power. After due consideration of the structural characters

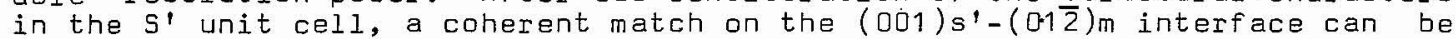
accepted and the reason why the secondary preferred growth direction of the $S^{\prime}$ laths should be the [010] axis is also understood.

\section{II - EXPERIMENT METHODS}

A commercial 2024 aluminium alloy containing 4.43 wt\% Cu, 2.00 wt\% Mg and 0.53 wt\% $M n$ was treated at the solid solution temperature of $495^{\circ} \mathrm{C}$ for $1 \mathrm{~h}$ in an air furnace and quenched in water at room temperature. Ageing treatments were carried out at $190^{\circ} \mathrm{C}$ for $6 \mathrm{~h}$ and $24 \mathrm{~h}$, respectively. Specimens usedfor electron microscopic study were prepared by the standard jet electron-polishing technique. They were then examined in the JEOL 200CX and JEOL 4000EX electronmicroscopes, the latter of which has interpretable resolution about $0.17 \mathrm{~nm}$. All HR images shown here were taken along the [100]m/[100] s' axes.

\section{III - RESULTS}

The S' precipitates in this alloy have two different morphology, i.e. fine rods with about $30 \mathrm{~nm}$ in length and several nanometers in diameter, which. were considered to be the strengthening precipitates, and the coarser laths which were preferentially nucleated at the helical and irregular lines of dislocations. Fig.1 shows a general view of the s' precipitates. According to the known orientation relationships the $S^{\prime}$ phase can form 12 possible variants in the f. c.c. aluminium matrix, and at least two variants have been shown in fig.1, where (001) lattice fringes in the $S^{\prime}$ laths are well resolved. The S' phases nucleated homogeneously in the matrix, which were shown to have rod shape with sections several nanometers in diameter, appear only with faint contrast because of their small dimension. In high magnified HR image, even the two dimensional [100]s' lattice image of rods was clearly seen but no certain interface structure between the $S^{\prime}$ and matrix can be defined. For the lath-shaped precipitates formed from heterogeneous nucleation the (010) $s^{\prime}-(021) m$ interfaces are rather too irregular (see fig.1 and the upper-left in fig.2a) and

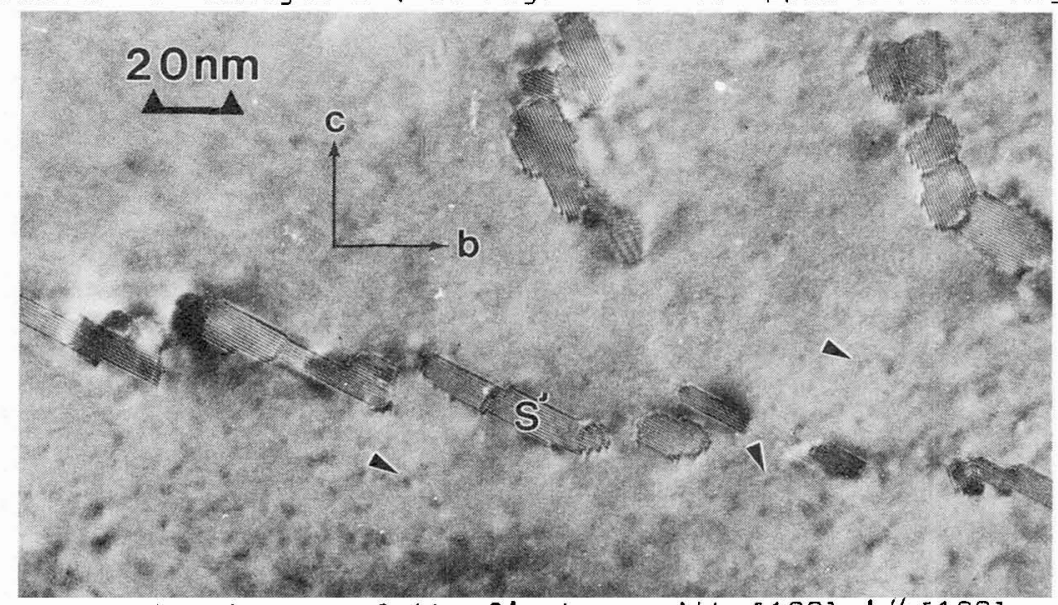

Fig.1 High-resolution images of the $S^{\prime}$ phase with [1001s'// [1001m. The homogeneous precipitates with several nanometers in diameter are indicated by arrows and the lath-shaped $S^{\prime}$ phases were formed at some imperfects in the $A 1$ matrix. The orientation has been marked in the matrix. The (001) lattice fringes are clearly seen in the $S^{\prime}$ laths and two $S^{\prime}$ variants can be detected in this region. 
then we will focus on the flat (001) $s^{\prime}-(01 \overline{2}) \mathrm{m}$ interface. Fig.2 gives two features on the (001) s'- $(01 \overline{2}) \mathrm{m}$ interface, i.e. coherent match along the [010]s' and $[021] \mathrm{m}$ directions in (a) and step structure in (b). In fig.2a the [1001m lattice image with a $0.202 \% 0.202 \mathrm{~nm}$ square can offer an accurate gauge not only for dimension but also for orientation. In the upper-ight part the [100] s' lattice image with a rectangular network having dimension of $0.46(\mathrm{doro})$ *0.71(dood) $\mathrm{nm}^{2}$ is also shown. Along the (001) s'-(012)m interface each (002)m lattice plane fringe (horizontal) and every two (020)m fringes (vertical) match one (020)s' fringe well. There are some ledge structures on both sides of the S'-Al interfaces in fig.2b. The step height is always $0.71 \mathrm{~nm}$, this is just a door interplanar spacing. The step varies from 4-6 times of dolo in width. Such an interface structure implies a possible step-growth mechanism of the si phase. Another (001) s'-(015)m interface structure is given in fig. 3 where every five (020)s' fringes and ten (020)m fringes are marked.
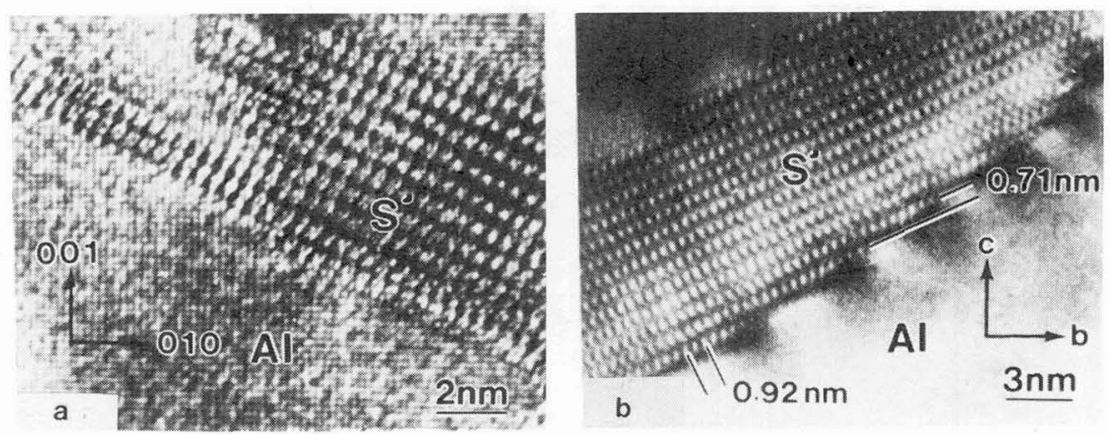

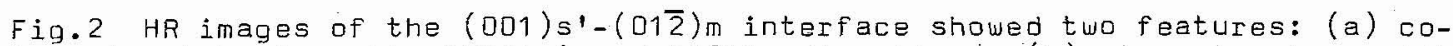
herent match along the [010] s' and [021]m directions; (b) step structure with single unitcell in height and 4-6 unitcells in width.

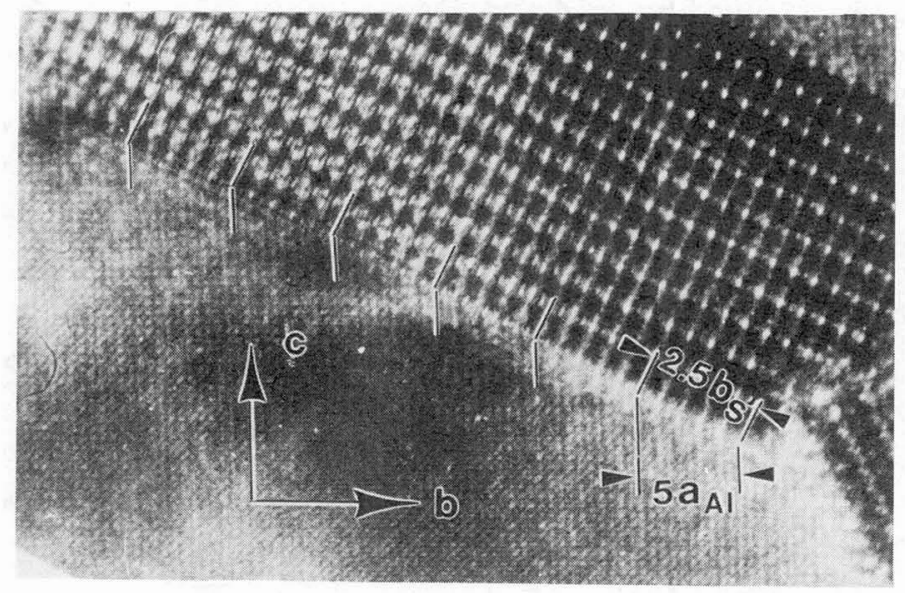

Fig.3 HR image of the flat (001) $s^{\prime}-(01 \overline{2}) m$ interface showed that every second (020)m plane joins one (020)s' plane.

In consideration of the plane misfit between the (020)s' and (020)m planes, the dimensions of the connection on the $(01 \overline{2}) \mathrm{m}$ plane are $\mathrm{r}[02 \mathrm{~m} / \mathrm{m} / 2=0.4527 \mathrm{~nm} \mathrm{for}$ every two (020)m planes and $d(020) s^{\prime}=0.461 \mathrm{~nm}$ for single (020) $\dot{s}^{\prime}$ plane. Then $\delta=\left(r\right.$ [021] $\mathrm{m} / 2-d(020) \mathrm{s}^{1} / \mathrm{r}$ [021] $\mathrm{m} / 2=-1.95 \%$ which is exactly the same as the expected value of the plane misfit between the (010)s' and (021)m planes. An advantage of consideration of the plane misfit between (020) $\mathrm{s}^{\prime}$ and (020)m planes is that it can be seen directly in the HR images as fig.2a and fig. 3 shown, but the (021)m lattice fringes are not resolved in the HR images at moment. According to the plane misfit value, every 23 (020)s' finges should match with 47 (020)m fringes. In contrast one can see perfectly coherent match between every two (020)m planes and one (020)s' plane within the region of 25 nm. Eor example, 


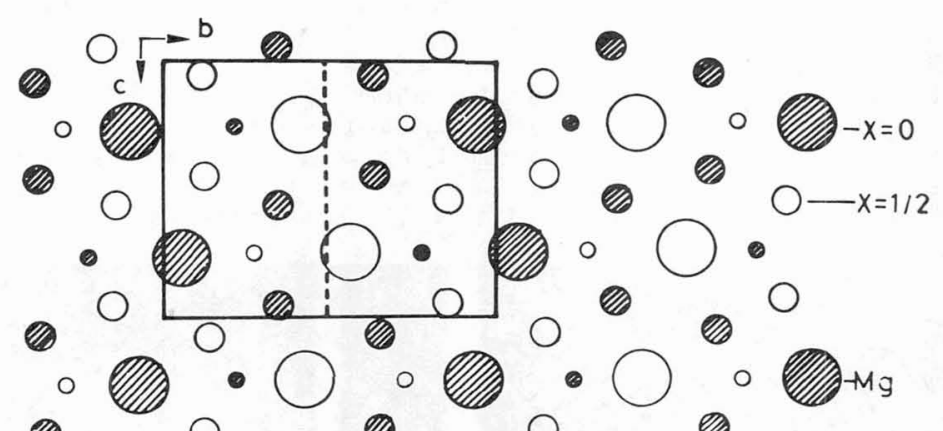

Fig. 4 View showing the atomic arrangement in the $S^{\prime}$ structure projected down [100] $s^{\prime}$.

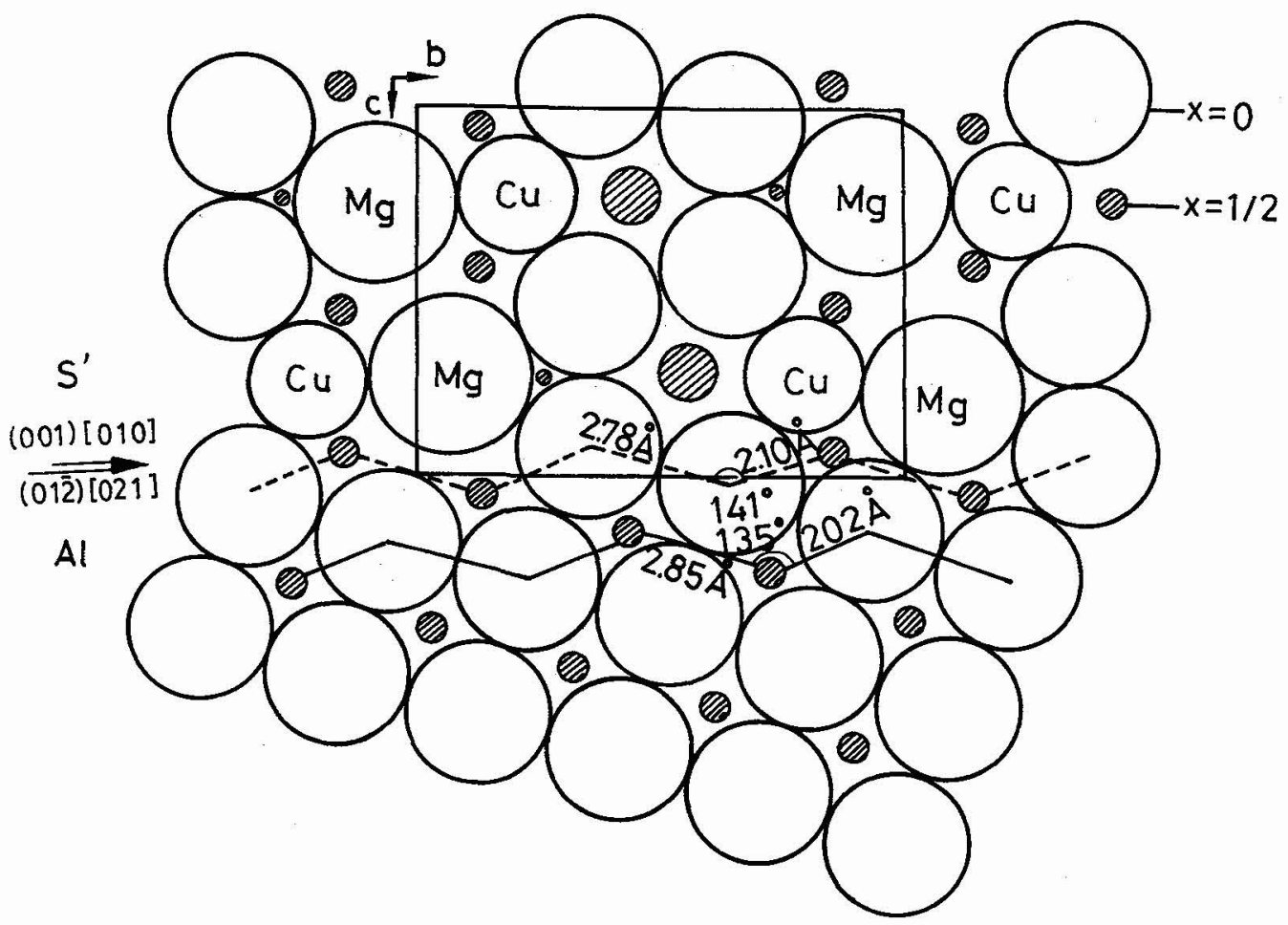

Fig.5 A proposed model of the $(001) \mathrm{s}^{\prime}-(01 \overline{2}) \mathrm{m}$ interface viewed doun [1001: large circles, Mg atoms; middle, Al; small, Cu; and open circles at $x=0$, solid at 
fig. $2 \mathrm{a}$ and fig. 3 both show 30 (020)s' fringes join exactly with 60 (020)m fringes, and no extra (020)m fringe can be detected. The fact of coherent match at the (001) s'-(012)m interface implies that the structural factors rather than the phenomenological geometry factors restrain the S'-Al interface structure.

IV - DISCUSSION

A [100] projected structure model of the $S^{\prime}$ phase shown in fig. 4 where the solid and open symbols represent the atoms located at $x=0$ and $\frac{1}{2}$, respectively. The S' phase has a layer structure along the (100) plane stacking with almost the same identical period as the (200)m interplanar spacing in the matrix. It is expected that there is completely coherent match on the (100) $\mathrm{s}^{\prime}-(100) \mathrm{m}$ interface. A unit cell of the $s^{\prime}$ phase has been outlined in fig. 4 and a b/2*c projected unit cell is also marked by dotted lines since there is a $C$ glide plane parallel to the $\vec{a}$ axis. Therefore we observed a $0.46 * 0.71 \mathrm{~nm}^{2}$ network in the [100]s' lattice image only, and no more information can be extracted within this rectangle because the distances of atom columns inside the unitcell are too close to be resolved even by a modern high resolution electron microscope. It is interesting to note that the distances of adjoining Al atom columns at the (100) s' (middle circles in fig.4) are 0.278 and $0.210 \mathrm{~nm}$, which coincide with the dimensions of $\sqrt{2} \mathrm{a} / 2$ and $a / 2$ in the $A 1$ matrix. A proposed (001) $\mathrm{s}^{\prime}-(01 \overline{2}) \mathrm{m}$ interface model thus was given in fig.5, where equal sphere packing in a (100)m plane and unequal spheres packing in the (100)s'plane
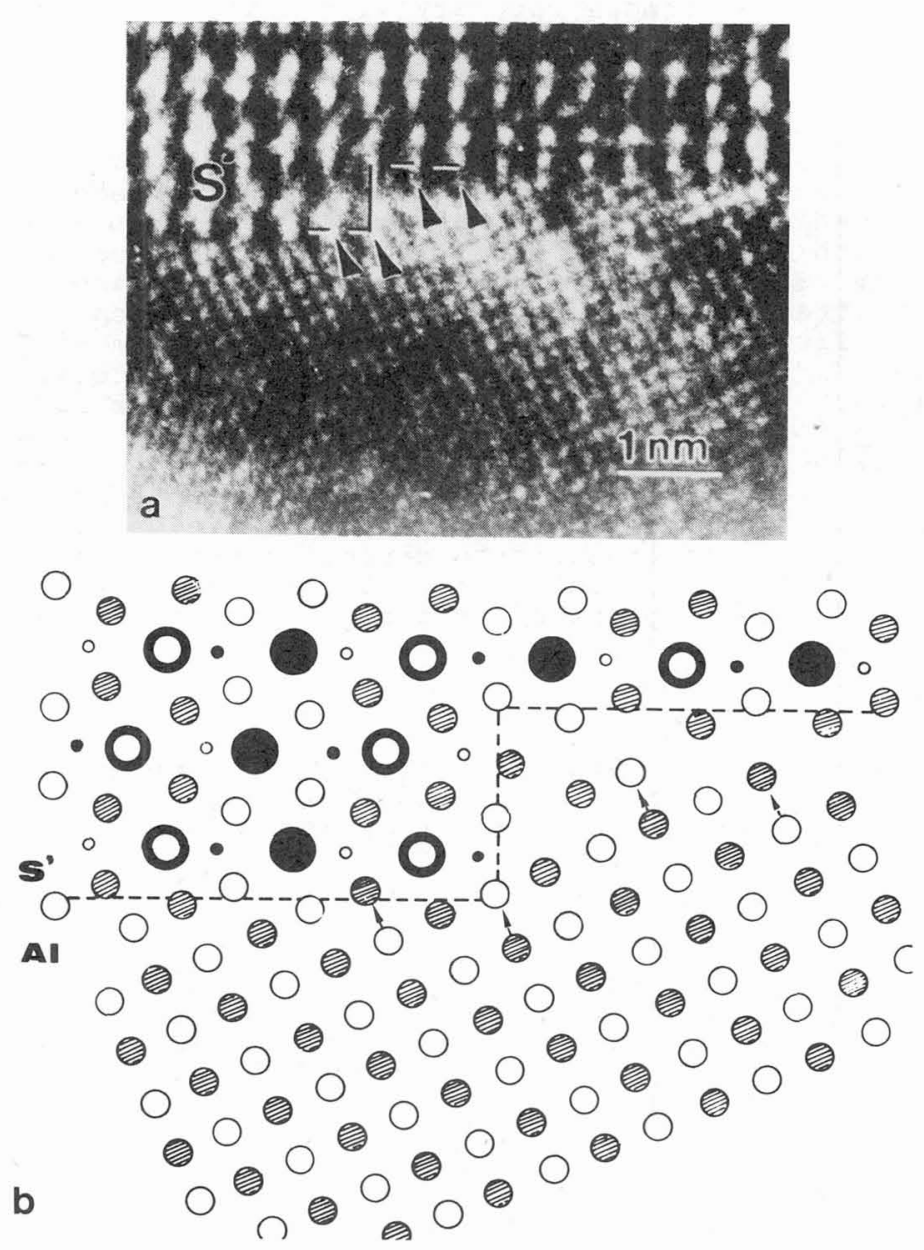

Fig. 5 The step structure of the (001) $s^{\prime}-(01 \overline{2}) \mathrm{m}$ interface: (a) HR image and (b) the corresponding structure model. 
were also shown. In the interface boundary as indicated by an arrow, slight distortion of the AI matrix is needed in order to connect the lattices with each other in coherence. The dotted line indicated those Al atom columns on the interface, which may belong to either the $S^{\prime}$ and $A 1$ matrix, and some parameters, which are intrinsic in the respective phases, are labelled also. From fig.5 it is clear that atomic attribute and the geometrical configuration in the s' unitcell allow a coherent connection with the Al matrix along the (001) s'-(012)m interface. In other hand, the property of keeping the configuration of the [021]m row in the [010] s' direction makes the [010] axis as the secondary prefered growth direction of the S' laths possible. Dur HREM observations well confirmed the proposed interface model. The HR image of the step structure on the (001) $s^{\prime}-(01 \overline{2}) \mathrm{m}$ interface and the corresponding structure model are given in figs.6a and b, respectively. Three (020)m lattice planes meet one (020)s' lattice plane on the step structure instead of every two $(020) \mathrm{m}$ planes on the flat interface. More distortion is expected at the (010) $\mathrm{s}^{\prime}$ interface of the step structure, and this perhaps is the reason why a step height is always as least as unitcell.

It should be noted that even the Al atom columns in the matrix werewell imaged in our HR images, the image dots in the 5' phase, however, represent the lat. tice nodes only. From the presented HR images, no more details about the atom arrangements inside the S' unit cell can be revealed. The match between the experimental image (Figs.2a, 3) and the proposed interface model (fig.5) is reasonable. Perhaps the extensively calculated images for the given model and some HR images for the interphase boundary with better resolution may offer more accurate information.

\section{V - CONClusions}

High resolution electron microscopy has been used to investigate the S' - Al interface structure in a 2024 aluminium alloy. For the lath-shaped $S^{\prime}$ phase formed from heterogeneous nucleation the $S^{\prime}$ lattice images show that the secondary preferred growth direction is the [010]' ' axis besides its longest [100] $s^{\prime}$ direction. The [1001s'/[100]m HR images reveal a good match in the flat

( 001$) s^{\prime}-(01 \overline{2}) m$ interface, and the coherent region may extent into about 25 nm, which is just the figure of the most probable width of the $5^{\prime}$ laths.Based upon a detailed analysis of atomic arrangements in the s' unitcell, it has been pointed out that the atomic configuration along the [021]m rous in the Al matrix fits quite well in the [010] s' rows of the S' phase. A structural model of the (001) s'-(01) $\mathrm{m}$ interface, thus, has been proposed, and a better understanding for S'-Al orientation relationships and the coherent match betweenthe $(020) s^{\prime}-(020) m$ plane connection, as well as the reason why the [010ls' axis should be the secondary preferred growth direction, can be accepted. The ledge structure on the (001) s'-(012)m interface with one unitcell in height and $4-6$ unitcells in width has been observed and a corresponding structural model is also presented.

\section{ACKNOWLEDGEMENTS}

The author would like to thank Professors M. Hirabayashi and K. Hiraga of HVEN Laboratory of Tohoku University for permission to use the resources of the facilities during his stay in Japan as fellowship of JSPS, which is also gratefully acknowledged.

\section{REFERENCES}

$11 /$ Bagaryatskii, Y.A., Dok1, Akad. Nauk SSSR, 87 (1952) 557.

$12 /$ Perlitz, H., and Westgren A., Ark. Kemi Miner. Coel., B, i6(1943) 13.

/3/ Wilson, R.N., and Partridge, P.G., Acta Metali., 13 (1965) 321.

/4/ Gupta, A.K., Gaunt, P., and Chatarvedi, M.C., Phil. Mag., A,55 (1987) 375. 